\title{
Unconcealed Questions*
}

\author{
Nicholas Fleisher \\ University of Wisconsin-Milwaukee
}

\begin{abstract}
Which price does John know? This sentence exemplifies what I call an unconcealed question (UQ): a sentence with a structure and meaning analogous to those of an ordinary concealed question (CQ), but where the sentence is interrogative in form and interpretation, with the relevant DP headed by which. Such examples are almost completely unstudied in the otherwise wide-ranging CQ literature. As I show, UQs exhibit a proper subset of the ambiguities that have been observed for ordinary CQs. In particular, UQs lack what is known as Reading B, where a relative clause (or other modifying adjunct) containing the relevant sort of predicate is interpreted in the scope of the higher CQ-selecting predicate (e.g. know). I survey the properties of UQs and evaluate the CQ theories currently on the market in light of the UQ data, concluding tentatively that the absence of Reading B is the result of syntactic factors whose description is straightforward but whose explanation remains murky.
\end{abstract}

Keywords: concealed questions, interrogatives, late merge

\section{Introduction}

Concealed questions (CQs) like (1) have generated considerable attention since Heim's (1979) classic paper. The present paper is devoted to the description and analysis of such sentences' interrogative counterparts, which I dub unconcealed questions (UQs), as in (2).

(1) John knows the price of milk.

(2) Which price does John know?

UQs behave similarly to classic CQs (in which the DP of interest is headed by the definite determiner) and to quantified CQs (headed by, e.g., every) in many respects. One notable way in which they differ, however, arises in cases where the nominal in question is modified by a relative clause that contains a CQ-selecting predicate

* I thank the SALT reviewers and audiences at SALT and UWM for valuable feedback. Particular thanks to Veneeta Dayal, Danny Fox, Polly Jacobson, Hadas Kotek, Hamid Ouali, Bernhard Schwarz, Gary Thoms, and Alexander Williams for their comments. The usual disclaimers apply. 
like know. Here, ordinary CQs (as well as quantified CQs) exhibit a well-known ambiguity in which the relative-clause material may be interpreted within the scope of the matrix CQ-selecting predicate or not, as sketched in (3). UQs, by contrast, disallow the reading (commonly called Reading B) where the relative-clause material is interpreted in the scope of that matrix predicate, as shown in (4).

(3) John knows the price that Mary knows.

a. Reading A: 'John knows the value of $p$, where $p$ is the price whose value Mary knows'

b. Reading B: 'John knows the identity of the price whose value Mary knows' / 'John knows which price it is that Mary knows'

(4) Which price that Mary knows does John know?

a. $\quad$ Reading A: 'for which price $p$ whose value Mary knows: John knows the value of $p$ ?'

b. \#Reading B: 'for which price $p$ whose value Mary knows: John knows that $p$ is a price whose value Mary knows?'

The observation that Reading B is missing in the UQ case is novel to the present paper, to the best of my knowledge. As I show, its absence is systematic, encompassing both the list and set readings of UQs, cases where the relevant predicate is expressed as an attributive adjective (rather than contained in a relative clause), and closely related examples headed by nonrelational nouns. The present paper thus serves as field guide to UQs, laying out the core facts against the CQ literature's rich empirical backdrop.

On the theoretical side, matters are somewhat less clear. I survey three prominent approaches to CQs and find them all unable to explain UQs' allergy to Reading B in a principled way. I tentatively conclude that its absence is due to syntactic factors, showing that a requirement for late merger of adjuncts in UQ DPs would derive the observed pattern, if such a requirement could be independently motivated.

\section{Empirical Overview of Interrogative CQs}

\subsection{CQ Readings}

Classic CQ examples include cases like those in (5). Syntactically, the CQ DP contains the definite determiner alongside a relational noun whose internal argument position is saturated. Semantically, the interpretation of the CQ DP is akin to that of a specificational copular clause (Romero 2005). (The meanings given in this section are pretheoretical paraphrases; I make no claim at this point for or against the idea that a CQ DP is actually interpreted as a specificational copular question.) 
a. John knows the price of milk.

'John knows what the price of milk is'

b. John knows the governor of Wisconsin.

'John knows who the governor of Wisconsin is'

As Heim (1979) observed, CQs support at least two kinds of interesting ambiguity. The first arises when the nominal inside the CQ DP is modified by a relative clause containing another CQ-embedding verb, as in (6). ${ }^{1}$ In such cases, the relative clause can either simply restrict the denotation of the nominal, leaving the relationship between the matrix verb and CQ DP otherwise unchanged; or it can become part of the concealed question itself, causing the understood question to be about the content of the relative clause rather than about the nominal it modifies. I follow much of the literature in calling these Reading A and Reading B, respectively. ${ }^{2}$

(6) John knows the price that Mary knows.

a. Reading A: 'John knows the value of $p$, where $p$ is the price whose value Mary knows'

b. Reading B: 'John knows the identity of the price whose value Mary knows' / 'John knows which price it is that Mary knows'

The second ambiguity noted by Heim can be seen in examples with determiners other than definite the. In (7), we get both a list reading, which semantically amounts to something like matrix-level quantification over the internal argument of the relational noun; and a set reading, where that internal argument is existentially bound off, the quantifier binds the relational noun's external argument, and we read matrix know as embedding a predicational copular clause. ${ }^{3}$

John knows every governor.

a. List: 'for every state $s$, John knows who the governor of $s$ is'

b. Set: 'for every governor $g$ of some state or other, John knows that $g$ is the governor of some state or other'

Unlike on the list reading, on the set reading of (7) John need not be able to successfully pair the governors with their states; he simply needs to know the

1 I follow standard practice by employing the same verb in both the matrix and relative clauses. The ambiguity arises just as well when the two verbs differ, e.g. John knows the price that Mary guessed.

2 To the best of my knowledge, these terms originate with Romero (2005). Frana (2017) calls Reading A the question reading and Reading B the metaquestion reading. Frana \& Rawlins (2011) call Reading A the what-value reading and Reading B the which-concept reading.

3 The list and set readings are often treated as involving quantification over individual concepts vs. quantification over individuals, respectively; for discussion, see Nathan (2006) and Frana (2017). We will adopt this convention starting in the next section. 
complete set of individuals who are governors. The intuition that the set reading involves questions about individuals, rather than about nominal relations or individual concepts, is reinforced by the fact that set readings are also available with saturated relational nouns and nonrelational nouns, as shown in (8) (Frana 2017).

a. John knows every representative from Wisconsin.

'for every representative $r$ from Wisconsin, John knows that $r$ is a representative from Wisconsin'

b. John knows every book that Mary read.

'for every book $b$ that Mary read, John knows that $b$ is a book that Mary read'

Finally, Aloni \& Roelofsen (2011) note that Heim's two ambiguities can be combined to form a four-way ambiguity for examples like (9), which supports A/list, $\mathrm{A} /$ set, $\mathrm{B} /$ list, and $\mathrm{B} /$ set readings. $^{4}$

John knows every governor that Mary knows.

a. A/list: 'for every state $s$ such that Mary knows who the governor of $s$ is, John knows who the governor of $s$ is'

b. A/set: 'for every governor $g$ of some state or other such that Mary knows that $g$ is the governor of some state or other, John knows that $g$ is the governor of some state or other'

c. B/list: 'for every state $s$ such that Mary knows who the governor of $s$ is, John knows that Mary knows who the governor of $s$ is'

d. B/set: "for every governor $g$ of some state or other such that Mary knows that $g$ is the governor of some state or other, John knows that Mary knows that $g$ is the governor of some state or other'

\subsection{UQ Readings}

UQs are similar to other nondefinite CQs in the range of readings they allow, with some important exceptions. UQ DPs happily originate in the object position of CQ-embedding verbs like know, as in (10). As with quantified CQ DPs, however, their internal argument position must not be overtly filled, as shown in (11).

$$
\text { Which price does John know? }
$$

4 Notably, we cannot mix and match the list and set readings in the matrix and relative clauses to form an eight-way ambiguity. For example, there is no available reading of (9) where for every state $s$ such that Mary knows who the governor of $s$ is (relative-clause/list), John knows (merely) that the governor of $s$ is the governor of some state or other (matrix-clause/set). This reinforces the impression that the list and set readings involve quantification over different (types of) variables. 
a. \#Which price of milk does John know?

b. \#John knows every price of milk.

UQs support the list-vs.-set ambiguity seen with ordinary quantified CQs. The sentence in (12) can ask either which state-governor relations John knows (list) or which individuals John knows to be governors (set). (As in the previous subsection, the meanings given here are pretheoretical paraphrases.)

Which governors does John know?

a. List: 'for which states $s$ : John knows who the governor of $s$ is?'

b. Set: 'for which governors $g$ of some state or other: John knows that $g$ is the governor of some state or other?'

When we turn to the Reading A-Reading B ambiguity, we find a major difference from ordinary CQs: UQs support Reading A but not Reading B. There is no available reading of (13) that asks about John's knowledge of Mary's price-knowledge.

Which price that Mary knows does John know?

a. Reading A: 'for which price $p$ that Mary knows: John knows $p$ ?'

b. \#Reading B: 'for which price $p$ that Mary knows: John knows that Mary knows $p$ ?'

The example in (13) most naturally supports list readings. We find an analogous disparity in cases that support set readings, like (14) (after Frana 2017).

(14) Which member of the Italian soccer team that Mary knows does John know?

a. A/set: 'for which MIST $m$ such that Mary knows that $m$ is a MIST: John knows that $m$ is a MIST?'

b. \#B/set: 'for which MIST $m$ such that Mary knows that $m$ is a MIST: John knows that Mary knows that $m$ is a MIST?'

Even in cases where the relative clause does not contain a CQ-embedding predicate - and where the Reading A-Reading B ambiguity is thus off the table-we find an intriguing parallel with the absence of Reading B. Consider (15), the UQ counterpart of $(8 b)$ :

? Which book that Mary read does John know?

a. \#'for which book $b$ that Mary read, John knows that $b$ is a book that Mary read?'

b. ?'for which book $b$ that Mary read, John knows that $b$ is a book?'

In (15), the relative clause cannot contribute to the predicational content of the set 
reading's understood embedded copular clause. Instead, only the modified nominal, book, can contribute to that predicational content, yielding a pragmatically awkward reading (insofar as it is awkward to ask, for a given book that Mary read, whether John knows that it is a book).

There is an interpretive asymmetry between the relative clauses found in (13), (14), and (15), which are barred from contributing semantically to the complement of CQ-embedding know, and the relational-noun complement PP found in (14), which is not. This asymmetry is found with UQs but not with ordinary quantified CQs; to the best of my knowledge, it has not previously been discussed in the literature.

\section{On the Absence of Reading B}

Now we can begin to get a bit more precise about the interpretation of UQs. In this section, we will sketch the meaning of UQs within a Hamblin/Karttunen semantics for questions. We will attend in particular to the matter of what material is interpreted within the question nucleus. This perspective affords a striking generalization: the missing readings of UQs-Reading B and certain set readings with nonrelational nouns-all share the property that the relevant material cannot be interpreted within the question nucleus, i.e. in the base position of the wh-moved DP. The task of capturing this generalization will guide the more detailed analysis and implementations in the next section.

We begin with basic cases like (10). Following Nathan (2006), Frana (2017), and many others, I treat price here as denoting a predicate of individual concepts, notated as PRICE IC. The concept predicate PRICE ${ }_{I C}$ characterizes a set of meaningfully sorted price concepts (the price of milk, the price of flour, etc.) and is derived from an underlying relational noun meaning via a type shift (Nathan 2006). Adopting for the moment a metalanguage shorthand where know can compose directly with an individual-concept argument, I sketch the meaning of (10) in (16).

$$
\begin{aligned}
& \llbracket \text { Which price does John know? } \\
& =\lambda p_{\langle s, t\rangle} \cdot \exists c_{\langle s, e\rangle}\left[\operatorname{PRICE}_{\mathrm{IC}}(c) \& p=\hat{\mathrm{J}} \text { knows } c\right]
\end{aligned}
$$

For set readings, I follow Nathan and Frana in assuming the existence of an indefinite object deletion (IOD) operator that existentially binds off the internal argument of a relational noun meaning, yielding a predicate of individuals. The difference between an individual-concept predicate meaning and an IOD-derived individual predicate meaning is shown in (17) for the relational noun governor. We can then characterize the difference between the list and set readings of a sentence like Which governor does John know? as in (18).

a. $\quad \mathrm{GOV}_{\mathrm{IC}}=$ the set of meaningfully sorted governor concepts (type $\left.\langle s e, t\rangle\right)$ 
Unconcealed Questions

b. $\mathrm{GOV}_{\mathrm{IOD}}=$ the set of individuals who are governors of some state or other (type $\langle e, t\rangle$ )

(18) Which governor does John know?

a. List: $\lambda p_{\langle s, t\rangle} \cdot \exists g_{\langle s, e\rangle}\left[\operatorname{GOV}_{\mathrm{IC}}(g) \& p=\hat{\mathrm{J}}\right.$ knows $\left.g\right]$

b. Set: $\lambda p_{\langle s, t\rangle} \cdot \exists x_{e}\left[\operatorname{GOV}_{\mathrm{IOD}}(x) \& p=\hat{\mathrm{J}}\right.$ knows that $\left.\operatorname{GOV}_{\mathrm{IOD}}(x)\right]$

In the set reading in (18b), the semantic content of the IOD-shifted nominal, $\mathrm{GOV}_{\text {IOD }}$, occurs within the question nucleus. It thus contributes to the clausal complement of know on this reading. Notably, this is precisely what relative-clause modifiers appear unable to do in UQs. As shown in (19), we can analyze the absence of both the B/list and the B/set readings as a failure of the material contributed by the relative clause (indicated via underlining) to occur inside the question nucleus.

Which governor that Mary knows does John know?

a. A/list: $\lambda p_{\langle s, t\rangle} \cdot \exists g_{\langle s, e\rangle}\left[\operatorname{GOV}_{\mathrm{IC}}(g) \& \underline{\mathrm{M} \text { knows } g} \& p=\hat{\mathrm{J}}\right.$ knows $\left.g\right]$

b. $\quad$ A/set: $\lambda p_{\langle s, t\rangle} \cdot \exists x_{e}\left[\operatorname{GOV}_{\mathrm{IOD}}(x) \& \underline{\mathrm{M} \text { knows that } \operatorname{GOV}_{\mathrm{IOD}}(x)} \& p=\hat{\mathrm{J}}\right.$ knows that $\left.\operatorname{GOV}_{\mathrm{IOD}}(x)\right]$

c. \#B/list: $\lambda p_{\langle s, t\rangle} \cdot \exists g_{\langle s, e\rangle}\left[\operatorname{GOV}_{\mathrm{IC}}(g) \& \underline{\mathrm{M} \text { knows } g} \& p=\hat{\mathrm{J}}\right.$ knows that $\left(\operatorname{GOV}_{\mathrm{IC}}(g) \&\right.$ M knows $\left.\left.g\right)\right]$

d. \#B/set: $\lambda p_{\langle s, t\rangle} \cdot \overline{\exists x_{e}\left[\operatorname{GOV}_{\mathrm{IOD}}\right.}(x) \&$ M knows that $\operatorname{GOV}_{\mathrm{IOD}}(x) \& p=\hat{\mathrm{J}}$ knows that $\left(\operatorname{GOV}_{\mathrm{IOD}}(x) \& \mathrm{M}\right.$ knows that $\left.\left.\operatorname{GOV}_{\mathrm{IOD}}(x)\right)\right]$

Focusing first on the set readings, we see that the available A/set reading in (19b) and the unavailable B/set reading in (19d) differ only in whether or not the relative-clause content is interpreted within the question nucleus, and thus within the scope of matrix know. While the nominal content contributed by governor can appear in this position, the content contributed by the modifying relative clause cannot. UQs differ in this respect from ordinary quantified CQs like the one in (9), which has a $\mathrm{B} / \mathrm{set}$ reading where the relative-clause content is interpreted within the scope of matrix know.

The situation with the list readings is somewhat more complex but casts the same overall shadow. On the available A/list reading in (19a), the relative clause restricts the concept variable but does not occur inside the question nucleus. On the unavailable B/list reading in (19c), the relative-clause content occurs inside the question nucleus, yielding a question about John's knowledge of Mary's knowledge of governor concepts. While the expression in (19c) is somewhat different from how Reading B is typically characterized in the literature, it is an accurate description of this type of reading. The sentence in (9), for example, has a B/list reading that we can paraphrase as 'for every governor concept $g$ such that Mary knows $g$, John 
knows that $g$ is a governor concept and Mary knows $g$ '.

What the unavailable $B$ readings have in common, then, is that the entire UQ NP content-nominal plus relative clause-is interpreted inside the question nucleus. The unavailability of these readings, together with the availability of the corresponding A readings, indicates that only the nominal content of the $w h$-DP may be interpreted in that DP's base position; the relative clause is limited to being interpreted in the landing site of $w h$-movement, where it restricts the variable introduced by the $w h$-DP. The interpretation of $w h$-moved DPs in UQs is strikingly different from that of QR-ed DPs in quantified CQs like (9), where the relative-clause content can be interpreted alongside the nominal in its base position within the scope of matrix know, yielding the B readings. The question, then, is what accounts for the difference between the two cases. Why, with the wh-movement found in UQs, is the relative clause's semantic contribution limited to restricting the relevant variable?

Before embarking on the analysis in the next section, let's consider a few additional data points with this perspective on Reading B in mind. First, relative clauses are barred from being interpreted inside the UQ question nucleus not just when they modify shifted relational-noun meanings like $\mathrm{GOV}_{\mathrm{IC}}$ or $\mathrm{GOV}_{\mathrm{IOD}}$, but also when they modify saturated relation nouns or nonrelational nouns. Here as well, Reading B is available with quantified CQs but not with UQs. As above, we can understand this as stemming from the relative clause's inability to be interpreted inside the question nucleus of a UQ, as sketched in (20) and (21).

(20) John knows every book that Mary read.

a. ??A: $\forall b_{e}: \operatorname{book}(b) \& \underline{\mathrm{M} \operatorname{read} b} \rightarrow \mathrm{J}$ knows that $\operatorname{book}(b)$

b. B: $\forall b_{e}: \operatorname{book}(b) \& \underline{\mathrm{M} \mathrm{read} b} \rightarrow \mathrm{J}$ knows that $(\operatorname{book}(b) \& \underline{\mathrm{M} \operatorname{read} b})$

(21) Which book that Mary read does John know?

a. ??A: $\lambda p_{\langle s, t\rangle} \cdot \exists b_{e}[\operatorname{book}(b) \& \underline{\mathrm{M} \operatorname{read} b} \& p=\hat{\mathrm{J}}$ knows that $\operatorname{book}(b)]$

b. \#B: $\lambda p_{\langle s, t\rangle} \cdot \exists b_{e}[\operatorname{book}(b) \& \underline{\mathrm{M} \operatorname{read} b} \& p=\hat{\mathrm{J}}$ knows that $(\operatorname{book}(b) \&$ $\underline{\mathrm{Mread}} b)]$

Second, the Reading A-Reading B disparity between UQs and quantified CQs is also found with modifiers other than relative clauses. The adjectival individualconcept predicate rising supports both Reading A and Reading B for the quantified CQ in (22) (focusing here on list readings), but Reading B is unavailable for the UQ in (23). Once again, the unavailability of Reading B is tied to a nominal modifier's inability to be interpreted within the question nucleus, i.e. in the base position of wh-movement within the scope of matrix know. ${ }^{5}$

5 These examples are modeled after an example from Frana (2017: 124). 
John knows every rising price.

a. $\quad \mathbf{A}: \forall c_{\langle s, e\rangle}: \operatorname{PRICE}_{\mathrm{IC}}(c) \& \operatorname{rising}(c) \rightarrow \mathrm{J}$ knows $c$

b. B: $\forall c\langle s, e\rangle: \operatorname{PRICE}_{\mathrm{IC}}(c) \& \underline{\operatorname{rising}(c)} \rightarrow \mathrm{J}$ knows that $\left(\operatorname{PRICE}_{\mathrm{IC}}(c) \&\right.$ rising $(c))$

(23) Which rising price does John know?
a. $\quad \mathbf{A}: \lambda p_{\langle s, t\rangle} \cdot \exists c_{\langle s, e\rangle}\left[\operatorname{PRICE}_{\mathrm{IC}}(c) \& \underline{\operatorname{rising}(c)} \& p=\hat{\mathrm{J}}\right.$ knows $\left.c\right]$

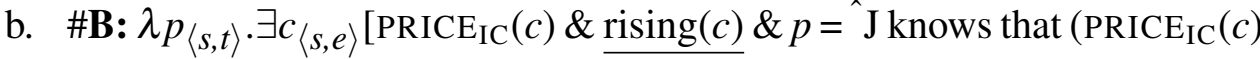 $\& \operatorname{rising}(c))]$

We thus see that B readings are systematically unavailable for UQs, and that this unavailability amounts to an inability for nominal-modifying material to be interpreted in the question nucleus, i.e. in the UQ DP's base position in the scope of matrix know. In the next section, we explore ways of accounting for this generalization.

\section{Possibilities for Implementation}

In this section we consider how to analyze and explain the data described in section 3. There is no consensus in the literature on the proper semantic analysis of CQs, and so below I sketch analyses in three prominent frameworks: the individual-concept framework of Romero (2005) and Frana (2017), the propositional framework of Nathan (2006), and the pragmatic framework of Aloni \& Roelofsen (2011). As I discuss below, I do not believe that the UQ facts weigh strongly in favor of one or another type of analysis of CQs. Rather, I take the systematic absence of Reading B in UQs to reflect a syntactic constraint that the various frameworks for CQ semantics must incorporate. A metric for comparing frameworks, then, is how naturally and nonstipulatively such a syntactic constraint can be brought on board.

\subsection{An Individual-Concept Approach}

On the CQ semantics adopted by Romero (2005) and Frana (2017), an ordinary definite CQ DP denotes an individual concept (type $\langle s, e\rangle$ ), and know composes directly with that DP as its internal argument (the notation in (24b) follows Nathan 2006 and Frana 2017). The semantic analysis of a basic example like John knows the governor of Wisconsin is sketched in (24).

a. $\llbracket$ know $\rrbracket=\lambda c_{\langle s, e\rangle} \lambda x_{e} \lambda w \cdot \forall w^{\prime} \in \operatorname{DOX}_{x, w}: c(w)=c\left(w^{\prime}\right)$

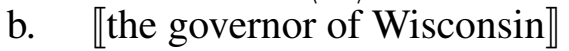

$=\lambda w . l x_{e} . x$ is gov. of Wisc. in $w$

$=\lambda w \cdot \mathrm{GOV}-\mathrm{WISC}(w)$

$=\mathrm{GOV}-\mathrm{WISC}$

(type $\langle s, e\rangle$ ) 


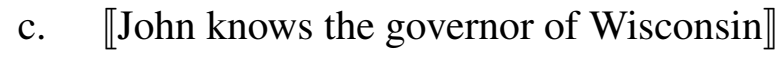

$=\llbracket$ knows $\rrbracket(\llbracket$ the governor of Wisconsin $\rrbracket)(\llbracket \mathrm{John} \rrbracket)$

$=\lambda w . \forall w^{\prime} \in \operatorname{DOX}_{j, w}: \operatorname{GOV}-\operatorname{WISC}(w)=\operatorname{GOV}-\operatorname{WISC}\left(w^{\prime}\right)$

The Reading A-Reading B ambiguity can be captured in this approach by adding a lexical entry for know that takes a type $\langle s, s e\rangle$ argument (an individual concept intension) and composing the VP via intensional function application (IFA; Heim $\&$ Kratzer 1998). ${ }^{6}$ To simplify the notation for (26), let us evaluate the expressions below at $w$ and stipulate that the unique governor concept that Mary knows at $w$ is the governor of Wisconsin (GOV-WISC). (For further details of this analysis, see Frana 2017.)

Two entries for know

a. $\llbracket$ know $_{s e} \rrbracket=\lambda c_{\langle s, e\rangle} \lambda x_{e} \lambda w \cdot \forall w^{\prime} \in \operatorname{DOX}_{x, w}: c(w)=c\left(w^{\prime}\right) \quad$ (as in (24))

b. $\llbracket$ know $_{s, s e} \rrbracket=\lambda C_{\langle s, s e\rangle} \lambda x_{e} \lambda w . \forall w^{\prime} \in \operatorname{DOX}_{x, w}: C(w)=C\left(w^{\prime}\right)$

John knows the governor that Mary knows.

a. $\mathbf{A}: \llbracket$ knows $_{s e} \rrbracket^{w}\left(\llbracket\right.$ the governor that Mary knows $\left.{ }_{s e} \rrbracket^{w}\right)\left(\llbracket \mathrm{John}^{w}\right)$ $=1$ iff $\forall w^{\prime} \in \operatorname{DOX}_{j, w}: \operatorname{GOV}-\mathrm{WISC}(w)=\operatorname{GOV}-\mathrm{WISC}\left(w^{\prime}\right)$

b. B: $\llbracket \operatorname{knows}_{s, s e} \rrbracket^{w}\left(\lambda w \cdot \llbracket\right.$ the governor that Mary knows $\left.\rrbracket_{s e} \rrbracket^{w}\right)\left(\llbracket \mathrm{John}^{w}\right)$ $=1$ iff $\forall w^{\prime} \in \operatorname{DOX}_{j, w}: \operatorname{GOV}-\mathrm{WISC}=\lg \langle s, e\rangle \cdot \operatorname{gov}\left(g, w^{\prime}\right) \& \mathrm{M} \operatorname{knows}_{w^{\prime}} g$

For cases where the CQ DP undergoes movement, Frana (2017) employs the copy theory of movement and (a tweaked version of) the Trace Conversion procedure of Fox (2002) to interpret the lower copy of the QR-ed CQ DP. Frana exploits the copy theory in her derivation of the A/set reading, which depends on late merger of the relative clause; early, pre-movement merger of the relative clause yields the $\mathrm{B} / \mathrm{set}$ reading instead (both set readings involve matrix know $w_{s e}$ ). The $\mathrm{A} /$ list vs. B/list distinction depends entirely on the use of knowse vs. knows,se, as sketched in (26); early vs. late merger of the relative clause has no interpretive effect, except insofar as late merger in combination with know s,se yields semantic anomaly (Frana 2010, 2017).

In order to derive the absence of Reading B for UQs within this framework, then, it would suffice to make late merger of the relative clause obligatory for the interrogative DPs in question. This would be harmless in the case of the A/list reading, criterial in the case of the $\mathrm{A} /$ set reading, and fatal in the cases of the two $B$ readings. ${ }^{7}$ Is there independent support for the idea that relative clauses must

6 The idea of using individual concept intensions to derive Reading B goes back to Heim (1979). The IFA implementation is an update by Frana (2017) to the analysis of Romero (2005).

7 The B/list reading would also be blocked if there were some independent reason why the lower copy of the wh-DP could not be composed with know $s$,se. It is unclear whether such a reason exists. 
merge late in $w h$-movement chains? Here, it seems, the behavior of UQs is out of step with other cases where late merger has been proposed. Late merger is often claimed to be available for adjuncts within a $w h$-moved DP, but it is not typically taken to obligatory (the standard arguments are based on binding evidence; see Fox \& Nissenbaum 1999; Fox 2002; Lebeaux 2009). While a late merger account could naturally explain the fact that it is adjuncts-both relative clauses and attributive modifiers like rising in (23) — that go missing from the wh-phrase's base position in UQs, further assumptions would be required in order to derive the apparent impossibility of such adjuncts' merging prior to wh-movement. ${ }^{8}$

To summarize: while an individual concept approach along the lines developed by Romero (2005) and Frana (2017) affords a natural way of deriving UQs' attested readings, it appears less successful in accounting for their unattested readings. If late merger of adjuncts is the grammatical mechanism for avoiding the B readings, then on standard assumptions about late merger, the unavailability of the B readings in UQs remains unexplained.

\subsection{A Propositional Approach}

Nathan (2006) develops a propositional semantics for CQs. In his analysis, a type $\langle e, e t\rangle$ relational noun like price undergoes a type shift that turns it into a function from type $e$ complements to question meanings. A CQ NP like price of milk then ends up denoting a Hamblin-style question meaning of type $\langle s t, t\rangle$, as sketched in (27) (Nathan 2006: 110).

$$
\begin{array}{ll}
\text { a. } & \llbracket \text { price } \rrbracket=\lambda y_{e} \lambda x_{e} \cdot y \operatorname{costs} x \\
\text { b. } & \text { SHIFT }(\llbracket \text { price } \rrbracket)=\lambda y_{e} \lambda p_{\langle s, t\rangle} \cdot \exists x_{e}[p=\hat{y} \operatorname{costs} x] \\
\text { c. } & \llbracket \text { price of milk } \rrbracket=\operatorname{SHIFT}(\llbracket \text { price } \rrbracket)(\llbracket \text { milk } \rrbracket) \\
& =\lambda p_{\langle s, t\rangle} \cdot \exists x_{e}[p=\hat{\text { milk costs } x]}
\end{array}
$$

In a sentence like John knows the price of milk, this question-like NP meaning composes with the definite determiner to yield the unique true proposition of the form 'milk costs $x$ ', which in turn serves as the argument of matrix know.

For CQs that contain a relative clause, like price that Mary knows, Nathan applies an existential closure operator to the shifted relational noun meaning shown above and intersects the result with the relative clause meaning. The result is the set of

Moreover, even if the $\mathrm{B} /$ list reading were blocked in this way, we would still need to appeal to something like obligatory late merger of the relative clause in order to derive the absence of the B/set reading, where the know se vs. know, se distinction is not at issue. For a summary of the mappings between the various LFs and the readings they yield within this framework, see Frana (2017: 146ff.).

8 Note as well: Reading B is unavailable even when the UQ DP remains in situ, as in multiple-wh questions like Who knows which price that Mary knows? 
propositions of the form ' $x$ costs $y$ ' that Mary knows, as sketched in (28). This meaning is fed to the definite determiner (or another suitable determiner, such as every) to derive Reading A along the lines discussed immediately above.

$$
\begin{aligned}
& \text { a. } \quad \exists \text {-CLO(SHIFT }(\llbracket \text { price } \rrbracket))=\lambda p_{\langle s, t\rangle} \cdot \exists y_{e} \exists x_{e}[p=\hat{y} \operatorname{costs} x] \\
& \text { b. } \quad \llbracket \text { price that M knows } \rrbracket=\lambda p_{\langle s, t\rangle} \cdot \operatorname{M~knows~} p \& \exists y_{e} \exists x_{e}[p=\hat{y} \operatorname{costs} x]
\end{aligned}
$$

To derive Reading B, Nathan employs an operator (which I call EMBED below) that wraps a question meaning like the one in (28b) in an "extra propositional layer" (Nathan 2006: 113). This yields a new question meaning, shown in (29), that can serve as input to the determiner and thence to know.

$$
\begin{aligned}
& \text { EMBED }(\llbracket \text { price that Mary knows } \rrbracket) \\
& \left.=\lambda q_{\langle s, t\rangle} \cdot \exists p_{\langle s, t\rangle}\left[q=\hat{(M} \text { knows } p \& \exists y_{e} \exists x_{e}[p=\hat{y} \text { costs } x]\right)\right]
\end{aligned}
$$

In Nathan's system, then, the availability of Reading B is tied to the application of the EMBED operator. The obvious challenge for employing this framework in the analysis of UQs is how to restrict the application of EMBED in an appropriate way. Nathan's system is designed to effect a kind of semantic reconstruction of the CQ NP material: for a quantified CQ like John knows every price that Mary knows, the CQ DP undergoes QR, but on Reading B its domain of quantification is a set of propositions of the form (M knows $p \& \exists y_{e} \exists x_{e}[p=\hat{y} \operatorname{costs} x]$ ), as in (29). Propositions of this form provide the values of the variable ranged over by every, and these in turn serve as the argument of matrix know in its nuclear scope. This succeeds in deriving Reading B for quantified CQs, but it is unclear how to restrict the application of this procedure for the structurally analogous interrogative UQs, where Reading B is unattested.

\subsection{A Pragmatic Approach}

Aloni \& Roelofsen (2011) develop a semantics for CQs in which the CQ DP's interpretation depends on the pragmatic resolution of several free variables. In their account, the CQ DP is shifted into a question meaning that serves as the argument of matrix know. The question operator ranges over the elements of a conceptual cover - a set of individual concepts that uniquely pick out each individual in the domain at a given index (Aloni 2001) — and the different CQ readings ( $\mathrm{A}$ and B, list and set, and various "mixed" readings within each category) are tied to different ways of resolving the relevant conceptual cover(s) and a free property variable introduced in the question type shift.

The proposal is motivated in part by the observation that CQ readings are tied not just to the type of implicit question involved, but also to the method of identification 
used to pick out the relevant individual (i.e. the individual found in the true answer to the question). Aloni \& Roelofsen discuss examples like John knows the winning card, where the card in question may be identified by suit, by physical location, or by some other salient method. Such distinctions are straightforwardly modeled via the use of conceptual covers. As Kalpak (2020) stresses, this pragmatic approach also offers a way of understanding how and why the availability of CQ readings crosscuts the grammatical distinction between relational and nonrelational nouns. When appropriately constrained, the pragmatic resolution mechanism may derive generalizations about the distribution of CQs more naturally than analyses based on syntactic or semantic nominal type (e.g. Nathan 2006; Barker 2016). (For reasons of space, I refer the interested reader to Aloni \& Roelofsen 2011 and Kalpak 2020 for formal details and discussion.)

Though this pragmatic framework is quite different in implementation from the individual-concept and propositional frameworks discussed above, it faces an analogous challenge in the analysis of UQs. B readings are derived by resolving the conceptual cover(s) and the free property variable in a particular way. In order to derive the observed distribution of B readings, the resolutions that deliver the (attested and available) B readings of John knows every governor that Mary knows must somehow be barred from yielding (unattested, unavailable) B readings for Which governor that Mary knows does John know? It is far from clear whether there are independently motivated grounds for achieving this. Conceptually speaking, it is clear what would be needed: it would have to be the case that the interrogative nature of UQs introduced some independent constraint on the resolution of the property variable, or were associated with some independent factor(s) leading to semantic or pragmatic anomaly in the resolution of the conceptual cover(s), in order to rule out $B$ readings of UQs in this framework. Absent such factors, the absence of UQ B readings remains mysterious here, as in the approaches considered earlier.

\subsection{Implementation: Summary}

Why do UQs lack B readings? No approach to CQs that I know of has a good answer to this question. There is no obvious reason why the mechanisms employed for deriving B readings of quantified CQs in the various frameworks discussed above should fail to extend to UQs. There does not appear to be any independent semantic problem with UQs: it is not the case, for example, that the elements of the question meanings in (19c) and (19d) all end up denoting the same proposition, or that we cannot identify a maximally informative true answer among them. B readings of UQs are, to all appearances, perfectly ordinary semantic objects. They just cannot be what those sentences mean.

These considerations, together with the fact that the Reading A-Reading B 
ambiguity is so intimately tied to the presence of adjunction, leads me to believe that the absence of B readings in UQs is most plausibly the result of some syntactic factor. While I do not have a concrete proposal to offer, I believe that the framework developed by Frana (2017) offers the most natural prospect for integrating a syntactic account. The correlation within her theory between the timing of an adjunct's merger and the type of reading that results offers most of what we need. All that remains is some account of why late merger (or a functionally equivalent mechanism) is not just possible for adjuncts in UQ DPs, but necessary. ${ }^{9}$

In this connection, it is worth mentioning another case where Reading B disappears in a particular syntactic configuration. Harris (2008) observes that Reading B is unavailable in antecedent-contained deletion (ACD) structures: the presence of VP ellipsis in (30b) disambiguates the sentence in favor of Reading A.

a. A, B: John knows every price that Mary knows.

b. A, \#B: John knows every price that Mary does.

Harris attributes the absence of Reading B under ACD to an interaction between the requirements of ellipsis and the structure of the relative clause. He proposes that Reading $\mathrm{A}$ is associated with a matching structure for the relative clause, that Reading B is associated with a raising structure for the relative clause, and that ACD requires a matching structure (Fox 2002; for background on matching vs. raising, see Bhatt 2002; Hulsey \& Sauerland 2006).

I take no position here on Harris's specific proposal about the relative-clause structures underlying Reading A and Reading B, as it appears not to shed much direct light on the matter at hand. It is not clear why the raising structure should be unavailable in an interrogative DP; and as we have seen in (23), Reading B vanishes in UQs even when the relevant adjoined constituent is not a relative clause at all. ${ }^{10}$ It is nonetheless suggestive that Reading B should prove sensitive to a syntactic phenomenon like ellipsis. Alongside the absence of any plausible semantic or pragmatic explanation for why Reading B should go missing in UQs, this suggests that future work might profitably seek an explanation at the syntax-semantics interface.

9 To clarify: late merger is but a particular way of implementing the kind of interpretive disparity between base position and landing site that seems to be implicated here. I must leave for future work the task of considering alternative implementations that may be on firmer syntactic ground (for some recent proposals, see Milway 2020; Zyman 2020). I am grateful to Gary Thoms (p.c.) for discussion.

10 Hamid Ouali (p.c.) points out that if one could defend a reduced-relative analysis of attributive adjectives like rising, then one might be able to pursue a Harris-style matching-vs.-raising analysis even for cases like (23). 


\section{Other Cases}

\subsection{Long-Distance List Readings}

In this section I briefly examine UQs that occur in multiple-wh questions. Such examples show the kinds of readings one would expect to find given the existence of the list vs. set ambiguity in UQs and what is known more generally about the derivation of multiple-wh questions. There is, however, an additional reading that we do not find outside of the multiple-wh context, one akin to what is found in so-called wh-triangles (Dayal 1996, 2002, 2016).

To begin, an example like (31) supports the two readings shown in (32), sketched in a family-of-questions semantics (Hagstrom 1998; Kotek 2018). The list reading yields a set of questions of the form 'which governor-concept does $x$ know?' (in the pretheoretical terminology of section 2: 'for which $s: x$ knows who the governor of $s$ is?'), one per individual $x$ in the domain of $w h o$; and the set reading yields an analogous set of questions of the form 'which governor-individual does $x$ know to be a governor-individual?'

Who knows which governor?

a. List: $\left\{\right.$ which GOV $_{\text {IC }}$ does John know?, which GOV IC does Mary know?, ...\}

b. Set: $\left\{\right.$ which GOV $_{\text {IOD }}$ does John know?, which GOV IOD $_{\text {does Mary }}$ know?,...\}

Intriguingly, there is a third reading of (31): a list reading on which the family of questions is keyed not to the $w h$-subject but to the internal argument of the UQ relational noun. This is sketched in (33).

(33) Long-distance list: $\{$ who knows who the governor of Wisconsin is?, who knows who the governor of Minnesota is?,...

On this long-distance list reading, the domain over which the elements of the question set exhaustively iterate-in other words, the wh-element that is subject to "domain cover," in the terminology of Dayal (2016: 96) — is not an overt whelement at all. Rather, it is the argument position occupied by which state in the paraphrase Who knows who the governor of which state is? On this reading, then, the multiple-wh UQ sentence (31) is interpreted like a $w h$-triangle configuration, in which a matrix $w h$-phrase occurs alongside an embedded multiple-wh question.

Dayal analyzes the long-distance list reading of $w h$-triangles via the use of a higher-order question meaning for the embedded multiple-wh question. We may follow her lead here for reading (33) of (31), with the UQ DP playing the role of the embedded multiple-wh question (as the paraphrase above suggests). To get the 
appropriate higher-order question meaning, we start with Nathan's shifted relationalnoun meaning, which forms an ordinary question meaning with the relational noun's internal argument position abstracted out, as in (34). We form a higher-order question by existentially quantifying over the abstracted-out internal argument, either directly, as sketched in the lexical entry for which ${ }_{\text {HIGHER }}$ in (35), or by binding a choice function variable, as suggested by Dayal (2016: 218ff.). The result is shown in (36).

$$
\begin{aligned}
& \text { SHIFT( } \llbracket \text { governor } \rrbracket)=\lambda y_{e} \lambda p_{\langle s, t\rangle} \cdot \exists x_{e}[p=\hat{x} \text { is the governor of } y] \\
& \llbracket \text { which }_{\text {HIGHER }} \rrbracket=\lambda \mathscr{P}_{\langle e,\langle s t, t\rangle\rangle} \lambda Q_{\langle s t, t\rangle} \cdot \exists y_{e}[Q=\mathscr{P}(y)] \\
& \lambda Q_{\langle s t, t\rangle} \cdot \exists y_{e}\left[Q=\lambda p \cdot \exists x_{e}[p=\hat{x} \text { is the governor of } y]\right]
\end{aligned}
$$

The higher-order question raises and induces functional dependency on who (Dayal 1996, 2002). The full sentence meaning in (37) gives us propositions tracing the graphs of functions from such questions to individuals in the domain of who; answers consist of conjunctions of propositions of the form ' $a$ knows who the governor of $y$ is', one per state. ${ }^{11}$ We thus derive the observed domain cover behavior just as Dayal does for long-distance list readings of $w h$-triangles.

$$
\begin{aligned}
& \lambda p \cdot \exists f_{\langle\langle s t, t\rangle, e\rangle}\left[p=\bigcap \lambda p^{\prime} . \exists q \in \llbracket(36) \rrbracket\left[p^{\prime}=\hat{\operatorname{know}}(f(q), \operatorname{ANS}(q))\right]\right], \\
& \text { where } f \text { is a function from questions in } \llbracket \text { which }_{\text {HIGHER }} \rrbracket(\operatorname{SHIFT}(\llbracket \text { governor } \rrbracket)) \\
& \text { to individuals in } \llbracket \text { who } \rrbracket
\end{aligned}
$$

This $w h$-triangle-style meaning is implemented in a Nathan-style propositional semantics. I must leave to future work the task of implementing this reading in the individual-concept and pragmatic approaches discussed in section 4 , along with a comparison of their relative merits.

\subsection{Depend}

Like ordinary CQ DPs, interrogative UQ DPs can occur in positions reserved for question-denoting constituents. I focus here on depend, which selects for such constituents in both its subject and object positions. Once again, ordinary CQs support a Reading A-Reading B ambiguity, while UQs support only Reading A.

To begin, imagine two scenarios: a "seasonal variation" scenario, in which John knows a price whose value fluctuates seasonally, e.g. the price of an agricultural commodity like pumpkins; and a "shopping habits" scenario, in which John habitually buys different things from different stores and knows those stores' typical prices for those things. Now consider the following examples:

11 Where $a$ is the individual to whom $f$ maps the question 'who is the governor of $y$ ?' for the value of $y$ in question. 
Unconcealed Questions

(38) a. The price that John knows depends on the season.

b. The price that John knows depends on the store he is shopping in.

c. The store where John goes shopping depends on what he needs to buy.

(38a) readily expresses Reading $\mathrm{A}$ in the seasonal variation scenario: the price that John knows (e.g. the price of pumpkins) is a price whose value depends on what season it is. (38b) naturally supports Reading B in the shopping habits scenario: the particular price concept that John knows depends on which store he is shopping in (e.g. in the bakery he knows the price of loaves, in the shoe store he knows the price of loafers, and so on). Each of these examples supports both Reading A and Reading $\mathrm{B}$, with appropriate adjustments to the understood scenario; the scenarios sketched here merely help bring out what I take to be the naturally more salient reading in each case. Finally, (38c) has a salient B-like reading in the shopping habits scenario, but lacks an A-like reading: what depends on John's purchasing needs here is not the store itself, but the matter of which store John goes shopping in. ${ }^{12}$

When we turn to the corresponding UQ cases, we see that Reading B is unavailable across the board:

a. Which price that John knows depends on the season?

b. ?Which price that John knows depends on the store he is shopping in?

c. \#Which store where John goes shopping depends on what he needs to buy?

(39a) expresses Reading A, in which we ask which of the prices that John knows is a price whose value depends on what season it is (a question for which a possible answer might be the price of pumpkins); but this sentence cannot express Reading B, where what depends on the season is the matter of which price it is that John knows. (39b) likewise has only Reading A, which requires a modicum of pragmatic effort to bring forth: it asks which of the prices that John knows is a price whose value depends on the store he is shopping in (a question that will be true of a price that exhibits variation from one store to the next). And (39c), which had only a B-like reading in the CQ case, is now totally infelicitous.

When we put CQ DPs that support the Reading A-Reading B ambiguity in both the subject and object positions of depend, as in (40a), we get a complete four-way $\mathrm{A} \times \mathrm{B}$ ambiguity: we can get a dependency between prices known by John and Mary (A-A), a dependency between John's price knowledge and Mary's price knowledge $(\mathrm{B}-\mathrm{B})$, or a dependency between the price known by one person and the other person's price knowledge (A-B or B-A). When we form the corresponding

12 I call these A-like and B-like readings, since the absence of a CQ-selecting predicate from the relative clause in (38c) precludes a proper Reading A-Reading B ambiguity. The absence of the A-like reading here is connected to the fact that the DP in question is headed by a nonrelational noun. 
multiple-wh question with interrogative UQ DPs, as in (40b), only the A-A reading (dependency between prices) survives.

a. The price that John knows depends on the price that Mary knows.

b. Which price that John knows depends on which price that Mary knows?

The interpretive disparity between CQs and UQs documented above with know thus persists with depend. While I do not sketch a concrete semantics for depend here, it appears that adjoined material is once again unable to be interpreted in the UQ DP's base position in the depend examples. I must save further consideration of these cases for future work. ${ }^{13}$

\section{Summary}

We are left in a somewhat unsatisfying position. We have a robust, systematic empirical generalization for which we lack a clear theoretical account. UQs' failure to support Reading B does not seem to be attributable to any independent semantic factor. There is nothing ill-formed, trivial, or infelicitous about asking which price whose value Mary knows is such that John can identify it as a price whose value Mary knows; yet this is not an available meaning of the sentence Which price that Mary knows does John know? In the absence of a clear semantic or pragmatic reason why this reading should be blocked, I have suggested tentatively that we appeal to syntactic factors. In particular, it seems we can successfully understand the lack of Reading B as deriving from obligatory late merger of adjoined material within the UQ DP; but the obligatoriness of late merger (to say nothing of its theoretical palatability) remains unexplained.

At present, then, it appears that UQs do not help us adjudicate among the various theories of CQs on the market. All of the theories considered in section 4 have problems blocking Reading B in UQs. It is my hope that the UQ data brought to light in the present paper may stimulate further work within these frameworks to account for the challenge posed by UQs. It will also likely be worthwhile to investigate the behavior of CQ vs. UQ DPs in a broader range of environments, beyond the argument positions of know and depend.

13 An important question for future work here is whether the unavailability of Reading B in the UQ depend cases is merely syntactic in nature (as I've suggested above for the know cases) or whether there is a deeper semantic problem. For example, is Reading B of (39b) — which we might paraphrase as 'for which price $p$ that John knows: the matter of whether $p$ is a price that John knows depends on the store where he goes shopping?'- -semantically deviant in some way? I note in this connection that the status of quantified CQs with depend is somewhat unclear: Reading B of Every price that John knows depends on the store where he goes shopping strikes me as intuitively quite difficult to access. If quantified CQs pattern together with UQs in the depend cases, rather than with definite CQs as in the know cases, then there may be deeper semantic issues to sort out here. 
Unconcealed Questions

\section{References}

Aloni, Maria. 2001. Quantification under conceptual covers. Amsterdam: University of Amsterdam Ph.D. dissertation.

Aloni, Maria \& Floris Roelofsen. 2011. Interpreting concealed questions. Linguistics and Philosophy 34(5). 443-478. doi:10.1007/s10988-011-9102-9.

Barker, Chris. 2016. Why relational nominals make good concealed questions. Lingua 182. 12-29. doi:10.1016/j.lingua.2016.01.002.

Bhatt, Rajesh. 2002. The raising analysis of relative clauses: Evidence from adjectival modification. Natural Language Semantics 10. 43-90. doi:10.1023/A:1015536226396.

Dayal, Veneeta. 1996. Locality in WH quantification: Questions and relative clauses in Hindi. Dordrecht: Kluwer.

Dayal, Veneeta. 2002. Single-pair versus multiple-pair answers: $W h$-in-situ and scope. Linguistic Inquiry 33. 512-520. doi:10.1162/ling.2002.33.3.512.

Dayal, Veneeta. 2016. Questions. Oxford: Oxford University Press.

Fox, Danny. 2002. Antecedent-contained deletion and the copy theory of movement. Linguistic Inquiry 33. 63-96. doi:10.1162/002438902317382189.

Fox, Danny \& Jon Nissenbaum. 1999. Extraposition and scope: A case for overt QR. In WCCFL 18, 132-144. Somerville, Mass.: Cascadilla Press.

Frana, Ilaria. 2010. Concealed questions. In search of answers. Amherst: University of Massachusetts Ph.D. dissertation.

Frana, Ilaria. 2017. Concealed questions. Oxford: Oxford University Press.

Frana, Ilaria \& Kyle Rawlins. 2011. Unconditional concealed questions and Heim's ambiguity. In SALT 21, 495-514. Washington, D.C.: Linguistic Society of America. doi:10.3765/salt.v21i0.2623.

Hagstrom, Paul. 1998. Decomposing questions. Cambridge, Mass.: MIT Ph.D. dissertation.

Harris, Jesse A. 2008. On the syntax and semantics of Heim's ambiguity. In West Coast Conference on Formal Linguistics (WCCFL) 27, 194-202. Somerville, Mass.: Cascadilla Proceedings Project.

Heim, Irene. 1979. Concealed questions. In Rainer Bäuerle, Urs Egli \& Arnim von Stechow (eds.), Semantics from different points of view, 51-60. Berlin: Springer.

Heim, Irene \& Angelika Kratzer. 1998. Semantics in generative grammar. Malden, Mass.: Blackwell.

Hulsey, Sarah \& Uli Sauerland. 2006. Sorting out relative clauses. Natural Language Semantics 14. 111-137. doi:10.1007/s11050-005-3799-3.

Kalpak, Hana. 2020. The semantics and pragmatics of nouns in concealed questions. Semantics and Pragmatics 13(7). doi:10.3765/sp.13.7.

Kotek, Hadas. 2018. Composing questions. Cambridge, Mass.: MIT Press. 
Lebeaux, David. 2009. Where does binding theory apply? Cambridge, Mass.: MIT Press.

Milway, Daniel. 2020. A workspace-based theory of adjuncts. Ms. https://ling.auf. net/lingbuzz/005281.

Nathan, Lance. 2006. On the interpretation of concealed questions. Cambridge, Mass.: MIT Ph.D. dissertation.

Romero, Maribel. 2005. Concealed questions and specificational subjects. Linguistics and Philosophy 28(6). 687-737. doi:10.1007/s10988-005-2654-9.

Zyman, Erik. 2020. Phase-constrained obligatory late adjunction. Ms., University of Chicago. https://sites.google.com/view/ezyman/publications.

Nicholas Fleisher

Department of Linguistics

University of Wisconsin-Milwaukee

P.O. Box 413

Milwaukee, WI 53201-0413

USA

fleishen@uwm.edu 